\title{
Cisplatina e ozônio adjuvantes à exérese cirúrgica de carcinoma de células escamosas corneana em um equino
}

\author{
Cisplatin and ozone adjuvant to surgical excision of corneal squamous cell carcinoma in a horse \\ Cisplatino y adyuvante de ozono para la escisión quirúrgica del carcinoma de células escamosas de \\ la córnea en un caballo
}

Recebido: 08/12/2020 | Revisado: 13/12/2020 | Aceito: 03/01/2021 | Publicado: 05/01/2021

\author{
Ivana Ferro Carmo \\ ORCID: https://orcid.org/ 0000-0002-8918-8649 \\ Universidade Federal de Alagoas, Brasil \\ E-mail: ferroivanaa@gmail.com \\ Rayane Caroline Medeiros do Nascimento \\ ORCID: https://orcid.org/0000-0002-4823-0775 \\ Universidade Federal de Alagoas, Brasil \\ E-mail: rayanemedeiros@ hotmail.com \\ Tabatha de Oliveira Cavalcante \\ ORCID: https://orcid.org/0000-0002-7833-2465 \\ Universidade Federal de Alagoas, Brasil \\ E-mail: tatah.escodro@gmail.com \\ Alane Rodrigues de Souza \\ ORCID: https://orcid.org/0000-0002-4846-3915 \\ Universidade Federal de Alagoas, Brasil \\ E-mail: alanerodriguesmedvet@hotmail.com \\ Lucas Santana da Fonseca \\ ORCID: https://orcid.org/0000-0002-5261-9695 \\ Universidade Federal de Alagoas, Brasil \\ E-mail: lucasfonseca1989@gmail.com \\ Danillo de Souza Pimentel \\ ORCID: https://orcid.org/ 0000-0002-2479-1818 \\ Universidade Federal de Alagoas, Brasil \\ E-mail: danilopimentel@gmail.com \\ Anaemilia das Neves Diniz \\ ORCID: https://orcid.org/0000-0001-5071-2995 \\ Universidade Federal de Alagoas, Brasil \\ E-mail: anaemilia.diniz@vicosa.ufal.br \\ Pierre Barnabé Escodro \\ ORCID: https://orcid.org/0000-0002-9409-660X \\ Universidade Federal de Alagoas, Brasil \\ E-mail: pierre.vet@gmail.com
}

\begin{abstract}
Resumo
O carcinoma de células escamosas (CCE) constitui uma neoplasia de epitélio escamoso que geralmente acomete as regiões da cabeça, orbital e genitais dos equinos. A irradiação solar é uma das principais causas, em especial nas áreas despigmentadas e desprovidas de pelos. $\mathrm{O}$ artigo a seguir relata o caso de um equino, macho, de 15 anos, que apresentou uma massa infiltrativa nodular por toda superfície corneana, sugerindo tecido de granulação aderido à córnea. Ao exame citológico a massa era indicativa de carcinoma de células escamosas. Inúmeras características medicinais do ozônio já são bastante reconhecidas e relatadas pela comunidade científica, entre elas: sua ação antioxidante, bactericida, fungicida, imunoestimulante, auxílio na cicatrização de feridas e atividade antitumoral. Visto isso, transcorreu-se a excisão cirúrgica, curetagem corneana, quimioterapia intralesional com utilização de cisplatina e ozonioterapia. O tratamento demonstrou que a excisão cirúrgica, associada ao uso de cisplatina e ozonioterapia no pós-cirúrgico, apresentaram resultados eficientes, com prognóstico favorável, visto que após dezoito meses da alta médica do animal, o proprietário não relatou recidiva.
\end{abstract}

Palavras-chave: Cirurgia veterinária; Medicina integrativa; Neoplasia; Quimioterapia.

\begin{abstract}
Squamous cell carcinoma (SCC) is a neoplasm of squamous epithelium that usually affects the head, orbital and genital regions of horses. Solar irradiation is one of the main causes, especially in depigmented and hair-free areas. The article reports the case of a male horse, aged 15 years, who had a nodular infiltrative mass over the entire corneal surface, suggesting granulation tissue adhered to the cornea. On cytological examination, the mass was indicative of
\end{abstract}


squamous cell carcinoma. Numerous medicinal characteristics of ozone are already well recognized and reported by the scientific community, among them: its antioxidant, bactericidal, fungicidal, immunostimulating action, aid in wound healing and antitumor activity. In view of this, surgical excision, corneal curettage, intralesional chemotherapy with the use of cisplatin and ozone therapy took place. The treatment demonstrated that the surgical excision, associated with the use of cisplatin and ozone therapy in the post-surgical period, showed efficient results, with a favorable prognosis, since after eighteen months of the animal's medical discharge, the owner did not report recurrence.

Keywords: Veterinary surgery; Integrative medicine; Neoplasia; Chemotherapy.

\section{Resumen}

El carcinoma de células escamosas (CCE) es una neoplasia del epitelio escamoso que suele afectar la cabeza, las regiones orbitaria y genital de los caballos. La irradiación solar es una de las principales causas, especialmente en las zonas despigmentadas y sin vello. El artículo relata el caso de un caballo macho, de 15 años, que presentaba una masa infiltrante nodular en toda la superficie corneal, sugiriendo tejido de granulación adherido a la córnea. En el examen citológico, la masa era indicativa de carcinoma de células escamosas. Numerosas características medicinales del ozono ya están bien reconocidas y reportadas por la comunidad científica, entre ellas: su acción antioxidante, bactericida, fungicida, inmunoestimulante, ayudando en la cicatrización de heridas y actividad antitumoral. Ante esto, se llevó a cabo la escisión quirúrgica, el legrado corneal, la quimioterapia intralesional con el uso de cisplatino y la ozonoterapia. El tratamiento demostró que la escisión quirúrgica, asociada al uso de cisplatino y ozonoterapia en el postoperatorio, arrojó resultados eficientes, con pronóstico favorable, ya que a dieciocho meses del alta médica del animal, el dueño no reportó recurrencia.

Palabras clave: Cirugía veterinaria; Medicina integrativa; Neoplasia; Quimioterapia.

\section{Introdução}

As enfermidades oftalmológicas apresentam diversas etiopatogenias e podem comprometer em diferentes graus a visão dos equinos. Essas doenças podem afetar todas as estruturas do olho, sendo acometidas de forma generalizada ou individualizadas por estrutura anatômica. O tratamento e a recuperação do paciente variam de acordo com o agente etiológico, estrutura acometida e gravidade do caso em questão (Lavach, 1990).

O carcinoma de células escamosas (CCE) é um tipo de neoplasia de epitélio escamoso, também intitulada por carcinoma espinocelular ou carcinoma epidermóide (Ramos, et al., 2007). São tumores solitários, de expansão indolente, localmente invasivos que podem ser observados em qualquer parte do corpo, mas, geralmente acomete a região da cabeça, região orbital e genitais dos equinos. A irradiação solar é uma das principais causas, em especial nas áreas despigmentadas e desprovidas de pelos (Chacur, et al., 2014). O CCE corresponde à neoplasia mais frequente nas estruturas oculares dos equinos (Crispin, 2004).

Existem vários tratamentos descritos em equinos, normalmente associando a excisão cirúrgica à diversas terapias adjuvantes, buscando melhor prognóstico e diminuição na taxa de morbidade neoplásica, visto que a taxa de recidiva é alta, principalmente em regiões que não apresentem alta margem de segurança tecidual após a retirada do tumor (Cotovio, et al., 2015; Kubler, et al., 1999; Lavach, 1990). A localização do tumor, tal como sua extensão acometendo estruturas adjacentes, influenciam nessa escolha, que no geral envolve remoção cirúrgica completa do tumor (Lavach, 1990).

Muitas vezes a excisão completa do CCE é inviável, devido às lesões extensas e profundas (Severin, 1996). Nestes casos, pode ser recomendada a crioterapia ou a aplicação intralesional dos fármacos quimioterápicos, como o 5-fluorouracilo ou a cisplatina. Outros tratamentos utilizados nestas situações, são a hipertermia e a radioterapia, apesar de se encontrarem menos acessíveis aos clínicos (Brooks, 1999; Dugan, 1992; Paterson, 1997; Severin, 1996).

Dentre as terapias integrativas utilizadas, a ozonioterapia pode ser indicada (Bocci, 2004), consistindo na utilização do gás de ozônio de forma local (soros e óleos) ou sistêmica (auto-hemoterapia e insuflação retal) (Haddad, 2006; Lage-Marques, 2008). Inúmeras características medicinais do ozônio já são bastante reconhecidas e relatadas pela comunidade científica, entre elas: sua ação antioxidante, bactericida, fungicida, imunoestimulante, auxílio na cicatrização de feridas e atividade antitumoral 
(Silva, et al., 2011). O principal mecanismo de ação do ozônio está diretamente relacionado à reação bioquímica que ocorre entre a interação do gás e os compostos orgânicos do organismo vivo (Garcia, et al., 2008). Este artigo tem por objetivo relatar o caso de um equino com CCE ocular que foi submetido à exérese neoplásica associada à aplicação intra-lesional de cisplatina e ozonioterapia pós-cirúrgica.

\section{Metodologia}

O presente trabalho trata-se de um relato de caso relevante de neoplasia em equino, realizado por meio de estudo de caso. De forma que descreve e analisa as particularidades a respeito dos métodos de diagnóstico, protocolo terapêutico instituído no caso do animal do presente artigo, bem como busca analisar a literatura a respeito de neoplasias oculares em equinos, terapêuticas indicadas e novas terapias. Esta pesquisa tem caráter qualitativo e descritivo, abrangendo pesquisas envolvendo terapêutica e diagnóstico de neoplasias em equinos nos últimos 20 anos. Os artigos citados foram obtidos em bases indexadas como, por exemplo, Capes, Scielo, Scopus, Science Direct, Elsevier. Tais artigos foram selecionados de forma qualitativa a respeito do objetivo geral. Em relação ao suporte metodológico, o presente artigo utilizou a metodologia descrita por Pereira, et al., (2018) e as normas da American Psychological Association (APA).

\section{Relato de Caso}

Um equino macho, de pelagem tordilha, de 15 anos de idade, da raça Mangalarga Machador, com $400 \mathrm{~kg}$, foi admitido no ambulatório do Grupo de Pesquisa e Extensão Equídeos da Universidade Federal de Alagoas (GRUPEQUIUFAL) com histórico de crescimento de uma massa ocular, que fora retirada há cerca de seis meses e apresentou recidiva de alta agressividade e crescimento rápido. Ao curso do exame clínico, verificou-se que todos os parâmetros físicos estavam dentro dos padrões da espécie.

À inspeção observou-se na região oftálmica um tecido de granulação de aspecto nodular, aderido à córnea e ocupando-a quase que integralmente. Mensurou-se o tamanho exato da massa que possuía as dimensões 3,4 mm de largura e $3,9 \mathrm{~mm}$ de comprimento, como mostra a figura a seguir (Figura 1).

Figura 1. A. Tecido de granulação exuberante em região ocular de um equino, nota-se a extensão da massa neoplásica recobrindo quase totalmente o olho; B. uso de paquímetro para avaliar as dimensões $3,4 \mathrm{~mm}$ de largura e 3,9 mm de comprimento da massa ocular.

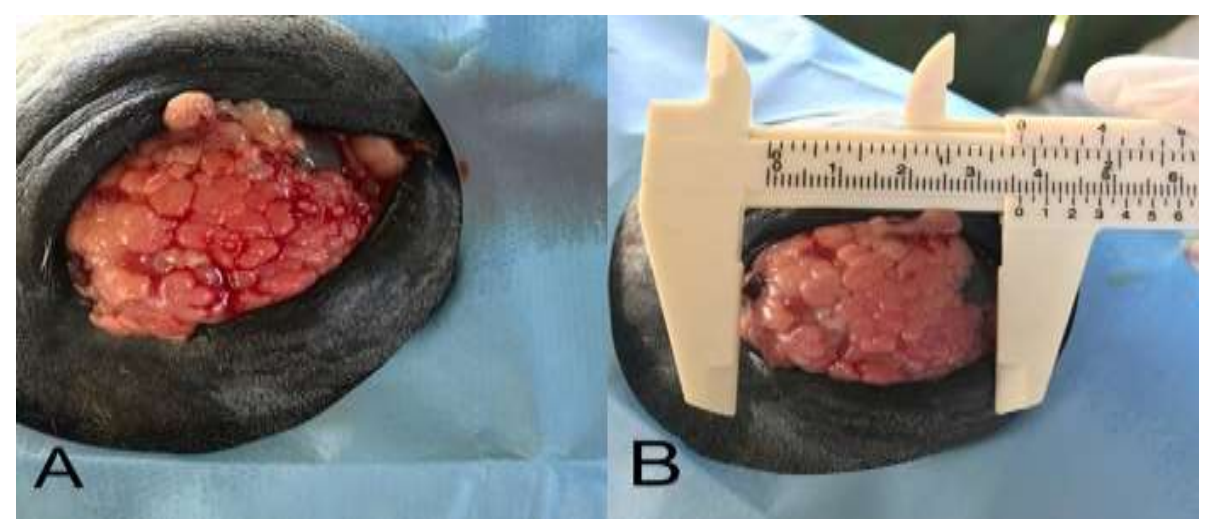

Fonte: Arquivo pessoal. 
A figura acima (Figura 1) foi realizada com o animal anestesiado, e pode-se notar a alta agressividade da neoplasia. Como está ocupando totalmente a órbita, o animal perdeu a visão deste lado temporariamente, o que o fez parar os exercícios físicos (passeios e cavalgadas) realizados pelo tutor. Este foi o principal motivo do mesmo buscar assistência veterinária. Para buscar os próximos passos e instituir a terapia mais adequada, foram realizados alguns exames diagnósticos como citologia oncótica, ultrassonogragia e histopatológico.

Ao exame citológico, indicado em casos que se existam presença de nódulos ou massas, foi avaliado alta celularidade nodular, observando-se anisocitose, cariomegalia, anisocariose, pleomorfismo celular e hipercromasia, (Figura 2) sugerindo o diagnóstico de CCE.

Figura 2. Lâmina de citologia aspirativa de Carcinoma de Células Escamosas ocular em equino. A. células apresentando cariomegalia e anisocariose; B. células apresentando pleomorfismo celular e hipercromasia.

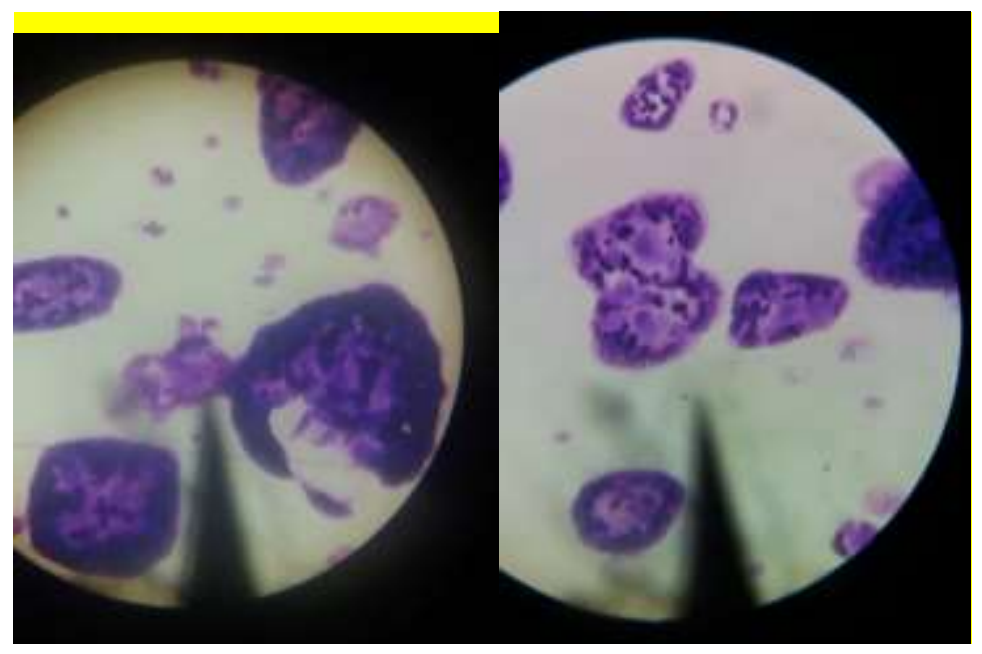

Fonte: Arquivo pessoal.

Por meio do exame citológico obteve-se o diagnóstico presuntivo de CCE, e a principal vantagem que se trata de um método pouco invasivo, e a partir dele pode-se planejar os próximos passos. O tratamento escolhido inicialmente foi o cirúrgico, porém, como não se tinha ideia do grau de invasibilidade da massa, para decidir entre uma técnica de enucleação e apenas excisão cirúrgica, optou-se pela realização da ultrassonografia. Para avaliar e decidir a melhor abordagem e técnica cirúrgica para o caso, foram realizadas duas técnicas de ultrassonografia oftálmica do globo ocular acometido, a transpalpebral e transcorneana (Martins, 2008; Matton, 2002), conforme a figura a seguir (Figura 3). 
Figura 3. Ultrassonografia (US) oftálmica em equino. A. Deslocamento do cristalino diagnosticado através de US oftálmica transpalpebral; B. Uso do recurso doppler para avaliação da vascularização e infiltração da massa neoplásica.

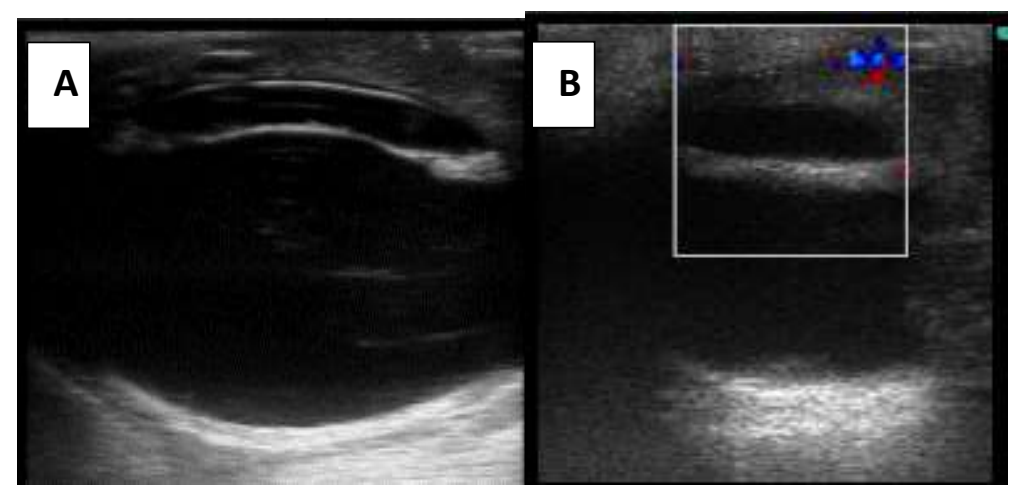

Fonte: Arquivo pessoal.

No exame ultrassonográfico, observou-se um deslocamento do cristalino a partir da sua localização anatômica correta. Essa subluxação também é conhecida como subluxação do cristalino ou Ectopia lentis, e pode ter ocorrido por provável infiltração neoplásica na órbita, mas como a infiltração era pequena optou-se pela excisão cirúrgica junto a terapias complementares.

Foi utilizado como protocolo anestésico: xilazina $0,5 \mathrm{mg} / \mathrm{kg} / \mathrm{IV}$ e o bloqueio do nervo lacrimal localizado de 0,5 a $1 \mathrm{~cm}$ acima da comissura lateral da pálpebra superior e supraorbitário localizado na emergência do forame supraorbitário, $6 \mathrm{~cm}$ dorsal a comissura medial do olho para analgesia da pálpebra superior; nervo zigomático localizado entre a comissura lateral e medial do olho de 0,5 a $1 \mathrm{~cm}$ ventral a pálpebra inferior, na porção supraorbitária do arco zigomático para analgesia de pálpebra inferior e comissura medial do olho (Merideth, et al., 1981; Skarda, et al., 1996; Maning, et al., 1976; Gaynor, et al., 1991); e nervo óptico encontrado na comissura medial do olho, tangencialmente ao globo ocular, rente ao tabique ósseo para analgesia retrobulbar (Massone, 1994) com $5 \mathrm{~mL}$ de cloridrato de lidocaína $2 \%$ sem vaso constritor em cada referência anatômica nervosa (Viana, 2007). Após latência de 15 minutos, realizou-se ressecção total da massa e curetagem de tecido remanescente aderido à córnea.

Imediatamente após a exérese neoplásica, realizou-se, com agulha 13x3,8 mm, aplicação de 0,5mL de cisplatina na concentração de $1 \mathrm{mg} / \mathrm{ml}$ nas bordas da ceratectomia e em tecidos remanescentes nas conjuntivas ( $1 \mathrm{~mL}$ ), além de administração subconjuntival de $2 \mathrm{~mL}$ de triancinolona $(20 \mathrm{mg} / \mathrm{mL})$. Dois dias após a cirurgia, foi realizado o teste de fluoresceína, teste diagnóstico de rotina, observando uma extensa úlcera de córnea confirmando lesão do epitélio, já esperada pela amplitude da curetagem e uso do quimioterápico, além de edema regional intenso. A evolução da úlcera de córnea foi acompanhada semanalmente, sendo observada sua diminuição gradual. O histopatológico da massa retirada identificou queratinócitos atípicos, graus variados de pleomorfismo celular e nuclear, e hipercromasia e infiltrado inflamatório predominantemente linfocítico, obtendo-se o diagnóstico sugestivo final de CCE.

O pós-cirúrgico foi realizado com uso imediato de dexametasona $(0,5 \mathrm{mg} / \mathrm{kg} / \mathrm{IM} / 1$ aplicação), fenilbutazona (4,4 $\mathrm{mg} / \mathrm{kg} / \mathrm{IV} / \mathrm{SID} / 5$ dias$)$, enrofloxacina (10 mg/kg diluído em soro IV/SID/5aplicações), máscara de proteção, crioterapia na região adjacente (10min/BID/5 dias), instilação de colírio de ciprofloxacino a 0,3\% (3 gotas/QID/14 dias) e ciclolato (3 gotas/BID/10 dias). Nova aplicação transcorneana de cisplatina foi realizada 14 dias após a cirurgia, com o intuito de inibir células neoplásicas residuais. 
A ozonioterapia foi realizada na forma de cupping (Figura 4) na concentração de $18 \mu \mathrm{g} / \mathrm{mL}$ por 5 minutos, a cada 3 dias, num total de 7 aplicações. A partir daí por mais 21 dias, foram instilados por via oftalmológica: soro autólogo (3 gotas/BID/15 dias), tobramicina a 0,3\% (3 gotas/BID/10 dias), atropina (3 gotas/TID/10 dias), colírio com solução de óleo ozônio 10 \% (3 gotas/TID/10 dias). O animal recebeu alta após 60 dias de internamento e monitoração diária, com a visão parcialmente normalizada e sem sinais de recidiva neoplásica após 18 meses da alta médica.

\section{Resultados e Discussão}

O animal do presente relato está de acordo com a faixa etária mais acometida pela doença, que varia entre 10 a 15 anos de idade (Scott, et al., 2004). Em casos como este recomenda-se a enucleação, como já relatado por Hendrix (2005). A opção por manter o globo ocular foi arriscada, devido a localização da massa e sua alta aderência a córnea. Como descrito por Severin (1996), nessas situações de lesões muito extensas e profundas é quase que impossível ter alta margem, o que traz prognóstico de reservado a ruim, com alta possibilidade de recidiva, não constatado no caso descrito.

Segundo Barros (2016), a exérese isolada não apresenta resultados satisfatórios, o que se fez com que a utilização de cisplatina intra-lesional aliado a ozonioterapia apresentasse sucesso terapêutico, preservando o globo ocular e retornando o animal à função (Kubler, et al., 1999). A ação da cisplatina resume-se na fase S, pois é nesta fase onde ocorre a síntese de DNA nuclear, além dos efeitos nas ligações cruzadas são mais evidentes. O quimioterápico entra na célula por difusão simples, dispensando a necessidade de um meio específico de transporte. Já dentro da célula, os íons de cloreto se dissociam e são substituídos por moléculas de água, resultando em uma forma aquosa, que então liga-se de forma covalente à hélice do DNA e inibe sua replicação (Deurloo, et al., 1991; Ogilvie, et al., 1991; Goldberg, et al., 2002; Hewes, et al., 2006).

Já a proposição do uso complementar ozônio em forma de cupping, propõe ação transitória de peróxido de hidrogênio na indução de citocinas em leucócitos, liberando-as em microambientes linfoides, acelerando o sistema imunológico que foi suprimido pelo crescimento do tumor, ou seja, agindo sinergicamente no local, com ações antineoplásica, bactericida, fungicida, analgésica e anti-inflamatória (Bocci, 2002; Larini, et al., 2005; Sunnen, 1998). O animal do presente trabalho obteve resultados satisfatórios com a ozonioterapia em forma de cupping conforme demonstra a figura a seguir (Figura 4).

Figura 4. A. Ozonioterapia ocular por meio de cupping de ozônio no pós-cirúrgico de equino submetido à exérese neoplásica; B. Olho do animal em processo de cicatrização com 30 dias de pós-cirúrgico.

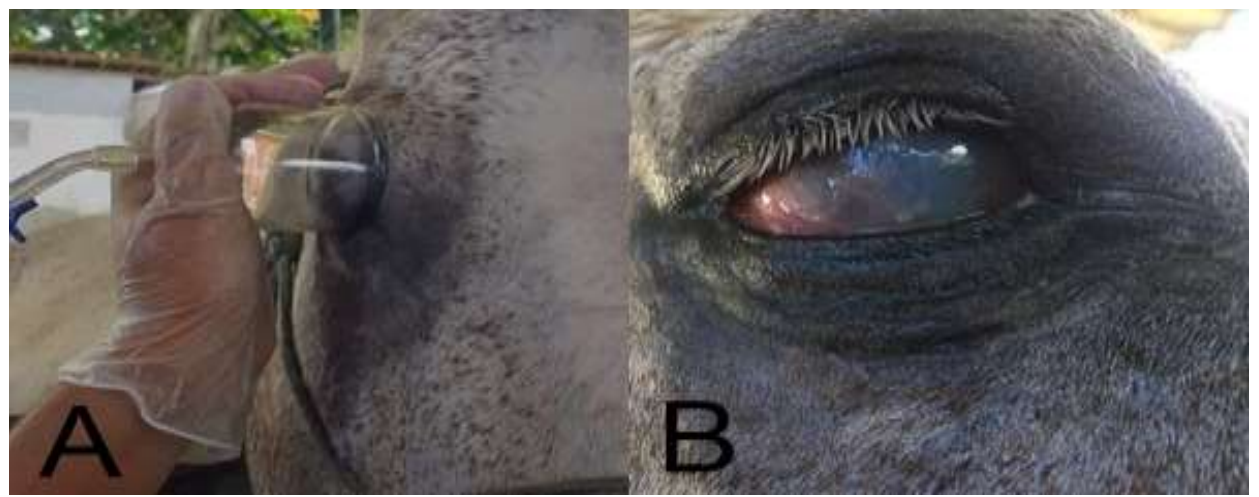

Fonte: Arquivo pessoal.

Explica-se em relação à atividade imunoestimulante, que o $\mathrm{O} 3$ consegue estimular a produção de anticorpos, fazer quimiotaxia e ativação de macrófagos e reduzir a resistência microbiana à ação fagocitária (Teresa, 2008), participando 
também da resposta inflamatória. Além de disso, por sua característica anti-hipóxia, o gás em contato com os tecidos aumenta a capacidade de glicólise, aumentando consequentemente o ATP celular e o transporte de O2 pela hemoglobina até os tecidos que encontram-se isquêmicos (Bocci, et al., 2011).

Assim, a atividade complementar do ozônio na terapêutica das neoplasias pode ser recomendada principalmente devido a seus mecanismos antiisquêmicos, pois sabe-se que a isquemia e hipóxia neoplásica é um ponto importante a se considerar na terapia do câncer. Outro ponto também é a resistência dos tumores aos tratamentos como quimio e radioterapia, levando ao avanço no crescimento neoplásico e aumentanto a chance de metástase dependendo da agressividade do tumor, mesmo durante a terapia. É importante ressaltar também que a ozônioterapia deve ser um tratamento adjuvante, complementar à terapia tradicional e não substituta (Vaupel, et al., 2007; Clavo, et al., 2018).

Além disso, sabe-se que as neoplasias estão frequentemente associadas à processos dolorosos muitas vezes crônicos, e afim de fornecer um controle analgésico adequado, os antiinflamatórios não esteroidais (AINES) são indicados. Os AINES atuam na cascata do ácido araquidônico bloqueando a via da cicloxigenase (COX), esta produz prostaglandinas que causam efeitos como inflamação, dor e febre e, ao boquear a cascata, os AINES vão reduzir tais efeitos (Rosa, 2016; Friton, et al., 2006). Acredita-se que a ozonioterapia é um método integrativo que promove analgesia ao potencializar o efeito dos fármacos ou por ser aplicado localmente na lesão. A grande vantagem desta terapia é não ser onerosa e ser eficaz para dor, apresentando raros efeitos colaterais (Viebahn-Hansler, et al., 2012).

No presente caso, após dezoito meses da alta médica do animal, o proprietário não relatou recidiva, diferindo de dois casos recidivantes citados por Vale, et al., (2012), onde o tratamento após exérese não surtiu efeito e pacientes foram submetidos à enucleação. Além disso, casos de CCE em equinos tem alto grau de recidivas, conforme citado por Giuliano, et al. (2008) e Rabo, et al. (2000), que mostraram taxas de recorrência de 44,4\% a 66,7\% em casos onde o tratamento instituído foi a cirurgia. Com isso, a terapia com ozônio e cisplatina associadas à exérese cirúrgica, mostrou-se eficiente no tratamento do carcinoma de células escamosas do caso relatado.

\section{Conclusão}

O artigo demonstrou que a excisão cirúrgica da neoplasia de córnea associada ao uso de cisplatina e ozonioterapia apresentou resultados eficientes no caso relatado, com prognóstico favorável. Por tratar-se de uma terapêutica complementar inovadora, novas pesquisas devem ser encorajadas na clínica de equinos, buscando avaliar a eficácia da ozonioterapia na supressão da prevalência de recidivas em casos de CCE na espécie após exérese, associadas ou não às terapias quimioterápicas.

\section{Referências}

Barros M. R. C., Escodro P. B, Souza F. W., Notomi M. K., Mata D. A. T., Lima A. M. S., Nascimento, R. C. M., \& Moreira, Y. F. (2016). Quimioterapia antineoplásica associada ao bloqueio perineural neurolítico no tratamento de carcinoma de células escamosas na face de um equino. R. bras. Med. Equina, 11(63), 04-08.

Bocci, V. (2002). Oxygen-Ozone Therapy. A Critical Evaluation. Kluwer Academic Publisher.

Bocci, V. (2004). Ozone as Janus: this controversial gas can be either toxic or medically useful. Mediators of Inflammation, 13(1), 3-11. https://doi.org/10.1080/0962935062000197083

Bocci, V. A. Zanardi, I., \& Travagli, V. (2011). Ozone acting on human blood yields a hormetic dose-response relationship. J Transl Med. 9(1), 66. https://doi.org/10.1186/1479-5876-9-66

Brooks, D.E. (1999). Section IV - Special Ophthalmology - 30. Equine Ophthalmology. In: Gelatt KN, editor. Veterinary Ophthalmology. (3a ed.), Lippincott Williams; Wilkins, 1053-1116.

Carneiro, P. C. A; Castro, O.F., \& Bertolazzo, W. (1992). Aspectos farmacológicos da cisplatina. Acta Cirúrgica Brasileira, 7 (3), $112-117$. 
Chacur, M. G. M, Fachini, B. A., Vamasaki, L., Basso, K., Sanches, O. C., \&Pessoa, V. M. (2014). Carcinoma das células escamosas no prepúcio com invasão vertebral em equino. Semina: Ciências Agrárias, 35(13), 83-88. https://doi.org/10.5433/1679-0359.2014v35n3p1383

Clavo, B., Santana-Rodriguez, N., Llontop, P., Guitiérrez, D., Suárez, G., López, L., Rovira, G., Martínez-Sánchez, G., González, E., Jorge, I., Perera, C., Blanco, J., \& Rodríguez-Esparragón, F. (2018). Ozone therapy as adjuvante for câncer treatment: is further research warranted? EvidenceBased Complementary and Alternative Medicine. 2018, 1-11. https://doi.org/10.1155/2018/7931849

Cotovio, M., Almeida O. C., Oliveira, J. P., Pereira, J. E., Paulo, J. R., Pena, M. T. (2015). Tratamento cirúrgico e médico (5 - flourouracilo) de um carcinoma das células escamosas na membrana nictitante de um cavalo. [Relato de caso]. Revista Portuguesa de Medicina Veterinária, 100(555-556), 229-21.

Crispin, S. M. (2004). Third eyelid and caruncle. Equine ophthalmology. In: Barnett, K.C. et al., (2a ed.), Saunders. 73-82.

Deurloo, M. J., Kop, W., Van Tellingen, O., Bartelink, H., \& Begg, A. C. (1991). Intratumouraladministration of cisplatin in slow-release devices: II Pharmacokinetics and intratumoural distribution. Cancer chemotherapy and pharmacology, 27(5), 347-353. https://doi.org/10.1007/BF00688856

Dugan, S. J. (1992). Ocular neoplasia. Vet Clin North Am Equine Pract, 8(3), 609-626. https://doi.org/10.1016/S0749-0739(17)30444-3

Friton, G. M., Philipp, H., \& Kleemann, R. (2006). Investigation of the clinical efficacy, safety and palatability of meloxicam (Metacam®) treatment in horses with musculoskeletal disorders. Pferdeheilkunde 22, 420-426.

Gaynor, J. S., \& Hubbell, A. E. (1991). Perineural and spinal anesthesia. Veterinary Clinics of North America: Equine Practice, 7(3), SOI-20.

Giuliano, E. A. Mcdonald, I., Mccaw, D. L., Dougherty, T. J, Klauss, G., Ota, J., Pearce, J. W., Johnson, P. J. (2008). Photodynamic therapy for the treatment of periocular squamous cell carcinoma in horses: a pilot study. Veterinary Ophthalmology, 11(1), 27-34. https://doi.org/10.1111/j.1463-5224.2008.00643.x

Garcia, C. A., Stanziola, L., Andrade, I. C. V., Naves, J. H. F., Neves, S. M.N., Garia, L. A. D. (2008). Autohemoterapia maior ozonizada no tratamento de erliquiose canina. [relato de caso]. In: Congresso Brasileiro de Medicina Veterinária, 35, Adaltech.

Goldberg, E. P., Hadba, A. R., Almond, B. A., Marotta, J. S. (2002). Intratumoral cancer chemotherapy and immunotherapy: opportunities for nonsystemic preoperative drug delivery. Journal of Pharmacy and Pharmacology, 54(2), 159-180. https://doi.org/10.1211/0022357021778268

Haddad, M. A. (2006). Efeitos da ozonioterapia sobre parâmetros clínicos, hematológicos e da bioquímica sanguínea em equinos. [Dissertação (Mestrado)]. Viçosa: Curso de Medicina Veterinária, Universidade Federal de Viçosa

Hayashi, M. P., \& Friolani, M. (2018). Aplicabilidade clínica cirúrgica da ozonioterapia em pequenos animais. [Revisão de literatura]. Revista Unimar Ciências, 27(1-2)

Hendrix, D. (2005). Equine Ocular Squamous Cell Carcinoma. Clinical Techniques. In equine practice. 4:87-94. https://doi.org/10.1053/j.ctep.2005.03.011

Hewes, C. A., \&Sullins, K. E. (2006). Use of cisplatin-containing biodegradable beads for treatment of cutaneous neoplasia in equidae: 59 cases (2000-2004). Journal of the American Veterinary Medical Association, 229(10), 1617-1622. https://doi.org/10.2460/javma.229.10.1617

King, T. C., Priehs D. R., Gum G. G., \&Miller T. R. (1991). Therapeutic management of ocular squamous cell carcinoma in the horse: 43 cases (1979-1989). Equine Vet J., 23(6), 449-452. https://doi.org/10.1111/j.2042-3306.1991.tb03759.x

Kubler, A. C., Haase T., Staff C., Kahle B., Rheinwald M., \& Muhling J. (1999). Photodynamic therapy of primary nonmelanomatous skin tumours of the head and neck. Lasers Surg Med; 25(1), 60-8. https://doi.org/10.1002/(sici)1096-9101(1999)25:1<60::aid-lsm8>3.0.co;2-x

Lage-Marques, M. (2008). Estudo da ozonioterapia como contribuição para a odontologia veterinária. [Dissertação (Mestrado)]. São Paulo: Curso de Medicina Veterinária, Universidade de São Paulo. https://doi.org/10.11606/D.10.2009.tde-17042009-161518

Lavach, J. D. (1990). Ch 16 - Ocular Neoplasia. In: Lavach, JD, editor. Large Animal Ophthalmology. St. Louis, EUA: C.V. Mosby Company;. $270-288$.

Lavach, J. D. (1990). Large animal ophthalmology. St Louis: Mosby. 395.

Larini, A., \& Bocci, V. (2005). Effects of ozone on isolated peripheral blood mononuclear cells. Toxicol In Vitro, 19(1), 55-61.

https://doi.org/10.1016/j.tiv.2004.06.007

Luna, S. P. L. (1998). Anestesias perineurais e regionais em equinos. Revista de Educação Continuada em Medicina Veterinária e Zootecnia do CRMV-SP, 1(1), 24-30. https://doi.org/10.36440/recmvz.v1i1.3392

Madej, P., Plewka, A., Madej, J. A., Nowak, M., Plewka, D., Franik, G., \& Golka, D. (2007). Ozonotherapy in an induced septic shock. I. Effect of ozonotherapy on rat organs in evaluatiron of free radical reactions and selected enzymatic systems. Inflammation. 30(1-2), 52-58. https://doi.org/10.1007/s10753-007-9021-7

Maning, J. P., \& St Clair, L.E. (1976). Palpebral frontal and zygomatic nerve blocks for examination of the equine eye. Veterinary Medicine, 71, 187-9.

Martins, B.C. (2008). Características ecográficas da lente cataratogênica senil em cães e sua correlação com parâmetros de facoemulsificação (Canis familiaris, LINNAEUS, 1758). [Tese de Doutorado] - Jaboticabal: Faculdade de Ciências Agrárias e Veterinárias, Universidade Estadual Paulista.

Massone, E. (1994). Anestesiologia veterinária, (2a ed.), Guanabara Koogan, 2S2.

Matton, J. S. (2002). Small animal diagnostic ultrasound. (2a ed.), W. B. Saunders Company. 
Merldeth, R. E., \& Wolf, E. D. (1981). Ophtalmic examination and therapeutic technjques in the horse. The Compendium of Continuing Education, 3(1) I, 426-33.

Nascimento, R. C. M., Graboschii, A. C. G, Fonseca, L. S., \& Escodro, P. B. (2020). Analgesia in donkeys: the state of the art. Research, Society and Development, 9(10). http://dx.doi.org/10.33448/rsd-v9i10.8773

Ogilvie, G. K., Straw, R. C., Powers, B. E., Cooper M. F., \& Withrow, S. J. (1991). Prevalence of nephrotoxicosis associated with a short term saline solution diuresis protocol for the administration of cisplatin to dogs with malignant tumors: 61 cases (1987- 1989). Journal of American Veterinary Medical Association, 199(5), 613-6.

Paterson, S. (1997). Treatment of superficial ulcerative squamous cell carcinoma in three horses with topical 5-fluorouracil. The Veterinary Record, 141(24), 626-628. http://dx.doi.org/10.1136/vr.141.24.626

Pereira, A. S., et al. (2018). Metodologia da pesquisa científica. [e-book]. Ed. UAB/NTE/UFSM. https://repositorio.ufsm.br/bitstream/handle/1/15824/Lic_C ompu tacao_M etodolog ia-Pesquisa-Cientifica.pdf?sequence=1.

Rabo, J. S., Usman, H. S., \& Kolo, Y. M. (2000). Studies on ocular squamous cell carcinoma among horses in Borno State, Nigeria. [Short communication]. African Journal of Biomedical Research, 3(1), 129-130.

Ramos, A. T., Norte, D. M., Elias, F., \& Fernandes, C. G. (2007). Carcinoma de células escamosas em bovinos, ovinos e eqüinos: estudo de 50 casos no sul do Rio Grande do Sul. Braz. J. vet. Res. anim. Sci., São Paulo, 44, 5-13. https://doi.org/10.11606/issn.1678-4456.bjvras.2007.26583

Rosa, B. L. (2016). Uso de Aines associados à antileucotrienos em pacientes asmáticos: seus riscos e alternativas. [Monografia (especialização)] Instituto de Tecnologia em Fármacos/Farmanguinhos, Fundação Oswaldo Cruz, Rio de Janeiro.

Scott D. W., \& Miller W. H. J. (2004). Dermatologia Equina. Inter-médica Editorial XXI- 2004. Buenos Aires-Republica Argentina, 625.

Severin, G. A. (1996). Ch 8 - Conjunctiva. In: Severin, G. A., editor Severin's Veterinary Ophthalmology Notes. Third Edition ed. Fort Collins: DesignPointe Communications Inc. 271-272.

Silva Junior, J. I. S. (2018). Ozonioterapia no tratamento de ferida contaminada em canídeo (CANIS LUPUS FAMILIARIS) - Relato de caso. Revista Investigação, 17 (4). https://doi.org/10.26843/investigacaov1742018p\%25p

Sunnen, G. (1998). Ozone in medicine: overview and future directions. Journal of Advancement in Medicine. 1(3), $159-174$.

Skarda, R. T. (1996). Local and regional anesthetic and analgesic techniques: Dogs. In: Thurmon, J. C., Tranquilli, W. J., Benson, G. J., eds. Lumb and Jones Veterinary Anesthesia. (3a ed.), Williams \& Wilkins.

Teresa, B., Wolanska, E., Cieszko-Buk, M., Orlowski, M., \& Chalas, R. (2008). Practical use of ozone in dentistry-comments. Ann Universitalis Maria CurieSklodowska Lubin-Polonia 63(28).

Vale, D. F., Luz, M. J., Ribeiro, S. N., Medina, R. M., D’Angello, A., Silva, T. O. B. da, Carvalho, C. B., \& Filippo, P. A. Di. (2012). Enucleação Transpalpebral para tratamento de carcinoma de células escamosas em equino: relato de dois casos. Revista Brasileira de Medicina Equina, 39 (1), $22-25$.

Vaupel, P., Hockel, M., \& Mayer, A. (2007). Detection and characterization of tumor hypoxia using pO2 histography. Antioxidants and Redox Signaling, 9 (8), 1221- 1235. https://doi.org/10.1089/ars.2007.1628

Viana, F A. B. (2007). Guia Terapêutico Veterinário. (2a ed.), Lagoa Santa: Gráfica Editora Cem.

Viebahn-Hansler, R., Fernández, O. S. L., \& Fahmy, Z. (2012). Ozone in medicine: the low dose ozone concept - guidelines and treatment strategies. OzoneSci.Eng. 34(6), 408-424. https://doi.org/10.1080/01919512.2012.717847 